\title{
Lateral torsional buckling of I-sections in grade 55 steel
}

\author{
J. E. DIBLEY
}

\section{Dr N. S. Trahair, School of Civil Engineering, University of Sydney}

The Author's valuable experimental evidence on the buckling of high strength steel beams may be used to evaluate the reliability of theoretical predictions where available. In other areas, the experimental results will provide data against which semiempirical design rules may be checked.

62. It is unfortunate that many theoretical predictions $s^{30,31,32}$ are for beams for which the load points are free to deflect laterally and twist. However, the test beams were prevented from deflecting and twisting at the load points. In this latter case, the centre portion acts as a beam under uniform moment, and is elastically restrained against lateral bending and warping by the side portions. The elastic critical moment $M$ for such a beam can be obtained as

$$
\frac{M k_{\mathrm{L}} L}{\sqrt{E I_{\mathrm{y}} G K}}=\pi \sqrt{1+\frac{\pi^{2} E \Gamma}{G K k_{\mathrm{L}}{ }^{2} L^{2}}} \quad \text {. . . . . . }
$$

where

$$
\frac{\beta_{\mathrm{L}}}{1-\beta_{\mathrm{L}}}=-\frac{\pi}{2 k_{\mathrm{L}}} \cot \frac{\pi}{2 k_{\mathrm{L}}}
$$

in which $\beta_{\mathrm{L}}$ is a parameter which describes the degree of the end restraints acting on the beam. ${ }^{31}$ For simply supported beams $\beta_{\mathrm{L}}=0$ and $k_{\mathrm{L}}=1$, while for rigidly restrained beams $\beta_{\mathrm{L}}=1$ and $k_{\mathrm{L}}=0.5$. Equation (10) has been derived by assuming that the restraints against lateral bending are equal to those against end warping, which is a reasonable assumption since both of these restraints induce flange bending. ${ }^{33}$ The solution of equation (10) is shown in Fig. 18. Since the most favourable situation is that of rigid end restraints, it follows that the least effective length factor is 0.5 . I am therefore at a loss to explain the extremely low effective lengths obtained by the Author from my papers. ${ }^{23.24}$ In ref. 23, the only case of a beam under uniform moment is that of a simply supported beam for which $k_{\mathrm{L}}=1 \cdot 0$, while in ref. 24 there is no case of a beam under uniform moment for which the critical moment is greater than that given by equation (9).

63. In order to calculate the critical moment for the centre span, it is necessary to determine the degree of end restraint $\beta_{\mathrm{L}}$, and this depends on the relative stiffnesses of the side spans and on the moments acting on these side spans. For example, two possibilities are indicated in Fig. 19, which demonstrates that for small ratios a/L the centre span is restrained by the side spans and $0.5<k_{\mathrm{L}}<1$. On the other hand, for large ratios $a / L$, the reverse is true, and $k_{\mathrm{L}}>1$. The actual effective length of the centre span can be determined from the principles of interaction buckling ${ }^{34.35}$ in which it is assumed that the interaction moments between adjacent spans automatically adjust themselves so that the critical moments of the individual members are equal to the applied moments which cause the complete beam to buckle.

64. When applying these principles, it is convenient to make use of solutions for the critical moments of the centre and end spans for a range of restraint parameters $\beta$. The solutions for centre spans are those of equations (9) and (10), and these are shown in Fig. 18. For end spans, solutions have been obtained by the method of finite integrals ${ }^{36}$ by techniques similar to those used for end spans with 




Fig. 18. Effective length factors for end and centre spans 



Fig. 19. Possible buckled shapes for test beams

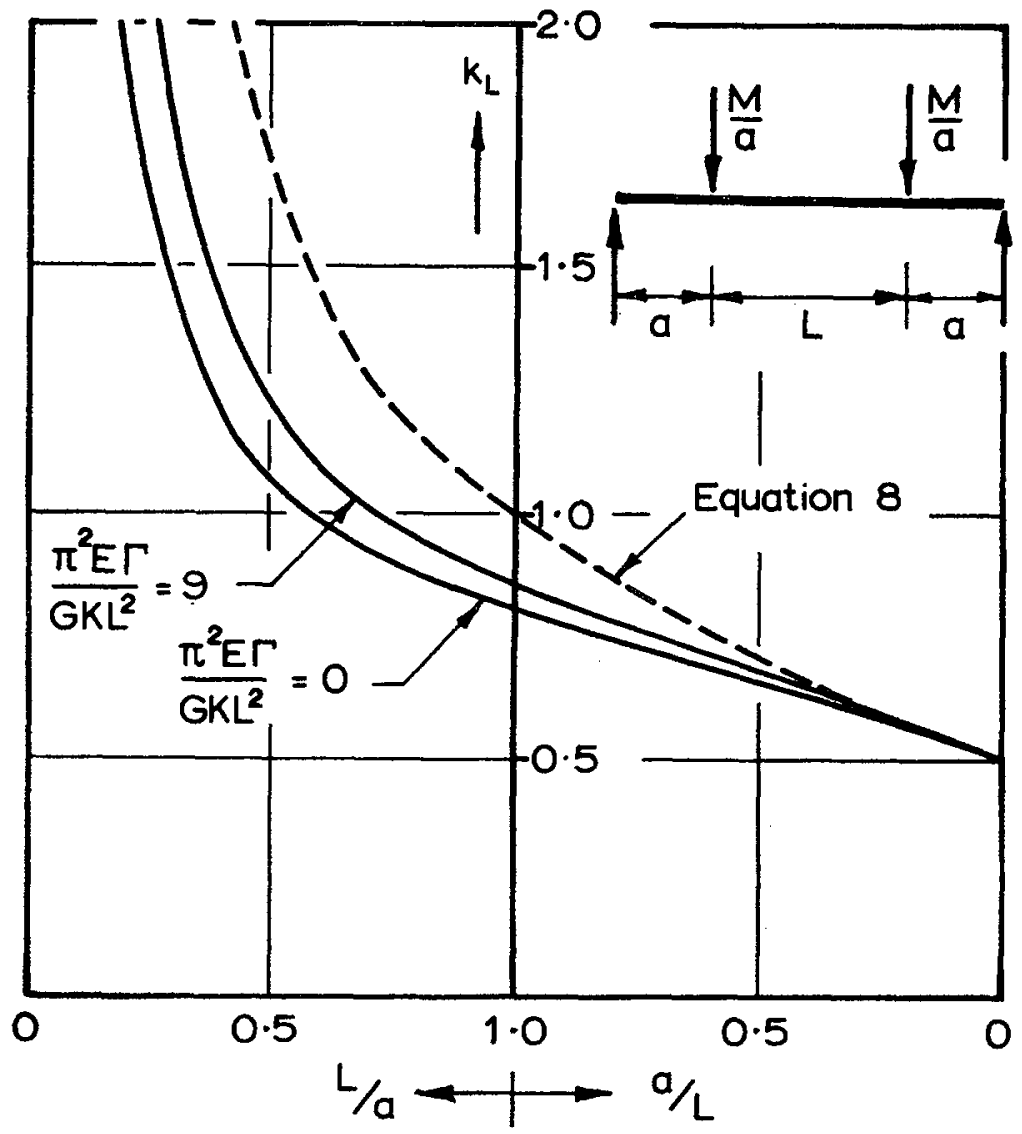

Fig. 20. Effective length factors for test beams 
central concentrated or distributed loads. ${ }^{32}$ These solutions are shown in Fig. 18 as effective length factors $k_{\mathrm{a}}$ given by

$$
\frac{M k_{\mathrm{a}} a}{\sqrt{E I_{\mathrm{y}} G K}}=\pi \sqrt{1+\frac{\pi^{2} E \Gamma}{G K k_{\mathrm{a}}{ }^{2} a^{2}}}
$$

for various values of the restraint parameter $\beta_{2}$.

65. The effective lengths of the centre portion of the test beams can be determined from the solutions for the centre and end spans shown in Fig. 18 by imposing the conditions of continuity and equilibrium at the span junctions. ${ }^{35}$ These conditions are satisfied when

and

$$
\beta_{\mathrm{L}}=\frac{-\beta_{\mathrm{a}} 3 L / 2 a}{1-\beta_{\mathrm{a}}(1+3 L / 2 a)}
$$

$$
\frac{k_{\mathrm{L}} L}{k_{\mathrm{a}} a}=\sqrt{\frac{1+\frac{\pi^{2} E \Gamma}{G K k_{\mathrm{L}}^{2} L^{2}}}{1+\frac{\pi^{2} E \Gamma}{G K k_{\mathrm{a}}^{2} a^{2}}}} \quad . \quad . \quad . \quad . \quad .
$$

Solutions for $k_{\mathrm{L}}$ which satisfy equations (12) and (13) are shown by the full lines in Fig. 20. These are plotted against the length ratio $a / L$ for values of $\pi^{2} E T / G K L^{2}$ equal to 0 and 9 . Also shown in Fig. 20, by the dashed line, is a plot of equation (8) which was used by the Author to determine approximate effective length factors. This equation is valid if all spans of the beam are under uniform moment, but since the end spans of the test beams are under moment gradients, the critical moments of these are underestimated, and conservative overestimates of $k_{\mathrm{L}}$ are obtained, as indicated in Fig. 20.

66. The ultimate moment capacity of an I beam depends primarily on

(a) its elastic critical stress $F_{0}=M / Z_{x}$

(b) its yield stress $Y_{\mathrm{s}}$

(c) its value of $b / 2 T \sqrt{F_{y} / E}$ which is significant in inelastic local buckling of the compression flange, ${ }^{37}$ and

(d) its shape factor $S=Z_{\mathrm{p}} / Z_{\mathrm{x}}$ which is chiefly dependent on the ratio $b / 2 T$.

67. The more significant of these quantities are the elastic critical stress $F_{0}$ and the yield stress $Y_{\mathrm{z}}$, and it should therefore be expected that the elastic ultimate stress

$$
F_{\mathrm{u}}=\frac{M_{\mathrm{r}}}{Z_{\mathrm{x}}} \cdot \cdot \cdot \cdot \cdot \cdot \cdot \cdot \cdot \cdot \cdot
$$

and the permissible working stress $\boldsymbol{P}_{\text {bo }}$ will depend principally on these quantities, except for short beams when the variation of $b / 2 T$ will be significant. This dependence can be shown graphically by plotting the dimensionless ratio $F_{\mathrm{y}} / Y_{\mathrm{g}}$ and $P_{\mathrm{bo}} / Y_{\mathrm{B}}$ against $\sqrt{Y_{\mathrm{s}} / F_{\mathrm{o}}}$ as in Fig. 21. For this purpose, the elastic critical stresses $F_{0}$ have been determined from Fig. 20 and equation (9) by using accurate values ${ }^{38}$ of the section properties. The quantity $\sqrt{Y_{\mathrm{s}} / F_{\mathrm{o}}}$ has been chosen because it is a convenient measure of the relative importance of yielding and buckling. For Euler columns, $F_{\mathrm{o}}=\pi^{2} E /\left(l / r_{\mathrm{y}}\right)^{2}$ and $\sqrt{Y_{\mathrm{B}} / F_{\mathrm{o}}} \propto\left(l / r_{\mathrm{y}}\right)$, so that $\sqrt{Y_{\mathrm{a}} / F_{\mathrm{o}}}$ for beams is similar in importance to the slenderness ratio $l / r_{\mathrm{y}}$ for columns.

68. The experimental stresses $F_{\mathrm{u}}$ plotted in Fig. 21 show good agreement with the elastic critical stresses $F_{\mathrm{o}}$ for $\sqrt{Y_{\mathrm{g}} / F_{\mathrm{o}}}>1$. There is a transition away from $F_{\mathrm{o}}$ for $0.6<\sqrt{Y_{\mathrm{s}} / F_{\mathrm{o}}}<1$ due to the effect of yielding, while the values of $F_{\mathrm{u}} / Y_{\mathrm{s}}$ tend towards a more constant value for $\sqrt{Y_{\mathrm{s}} / F_{\mathrm{o}}}<0.6$, corresponding to full plasticity.

69. Also shown in Fig. 21 are the permissible working stresses $P_{\text {bo }}$ specified in the Australian Code AS CA1 : $1968 .^{39}$ The formulae given in Fig. 21 are for three different regions of $\sqrt{Y_{\mathrm{s}} / F_{\mathrm{o}}}$ which correspond closely to those described above. 


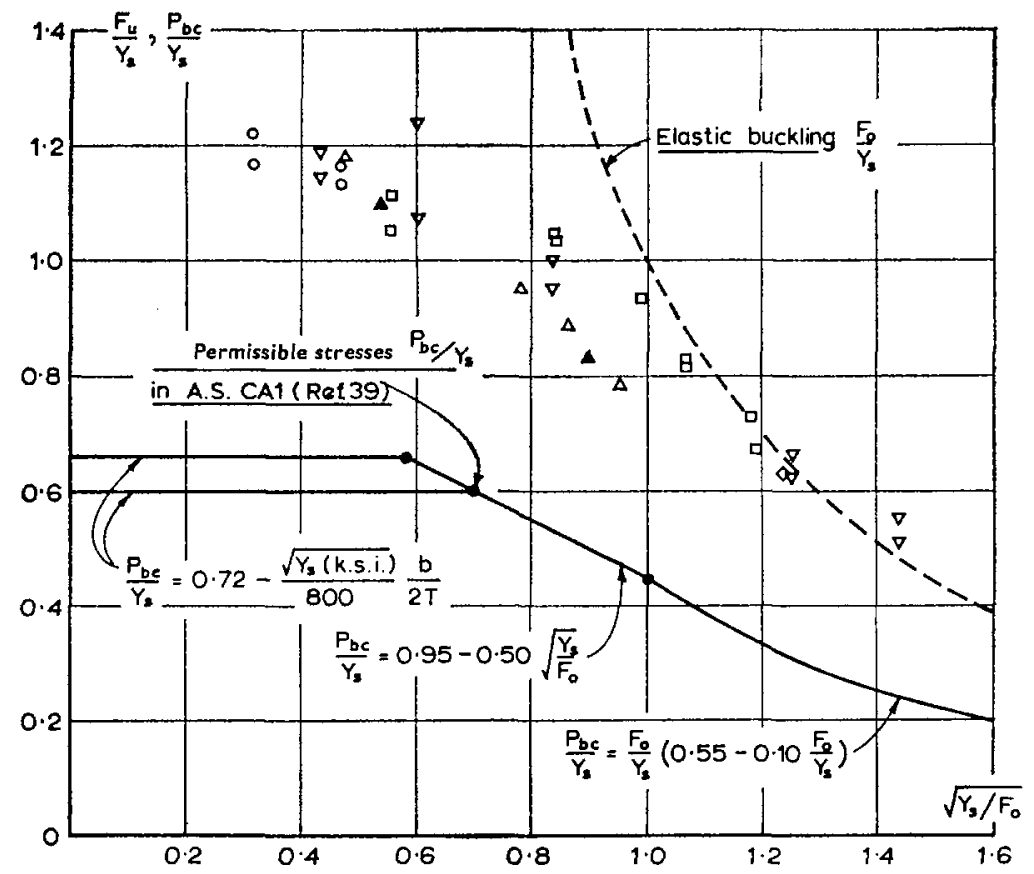

Fig. 21. Plots of $F_{\mathrm{u}} / Y_{\mathrm{s}}$ and $P_{\mathrm{bc}} / Y_{\mathrm{s}}$ against $\sqrt{Y_{\mathrm{s}} / F_{\mathrm{o}}}$

The shape of the curve plotted is in good agreement with the values of $F_{\mathrm{u}} / Y_{\mathrm{g}}$, and indicates a minimum factor of safety against collapse of about $1 \cdot 65$.

\section{Mr A. N. Procter}

Owing to the higher yield strength of the material, it was possible to extend the tests over a wide range of stresses. On the other hand the theoretical background carries us back some 30 or more years, when there was only a small amount of data available on the torsional properties of RS I-beams. That was why at that time the $T / D$ ratio was introduced into a formula ${ }^{10}$ surprisingly similar in form to formula 2 . The differences are that provision was made in the original formula for the conditions of loading and also that the safe stress, $C_{\mathbf{s}} / F$, was estimated instead of the critical stress $C_{\mathbf{B}}$. Using the Author's notation the original formula would have been

$$
\frac{C_{8}}{F}=\frac{40500 . C^{2}}{\left(l / r_{y}\right)^{2}}\left\{\sqrt{\left[1 \cdot 0+\frac{1}{3 \cdot 3 C^{2}}\left(\frac{l . T}{r_{7} D}\right)^{2} \mp 1 \cdot 0\right]}\right\} . .
$$

where the coefficient, $C$, referred to the conditions of loading, while the final $\mp 1.0$ provides for the application of the load to the top ( - ) or bottom ( + ) flange of the girder. In the present instance these two refinements do not apply to the tests, where uniform bending was used. Formulas of this type were only intended to apply to slender I-beams or to built up I-girders. They do not in fact apply with any degree of accuracy to column sections, such as were used in these tests. About 20 years ago the torsion constants, $K$, of RSJ's, based on actual tests, were published. ${ }^{11}$ Likewise the Bethlehem Steel Company ${ }^{42}$ have published the torsion constants, $K$, of universal 
beam and column sections, and also the values of $\pi / Z \sqrt{E I_{y} / G K}$ for steel members. These tabulated values enable formula 1 to be used without a great deal of difficulty for beam and column sections, giving greater accuracy than formula 2 . The measurement of the lateral deflexions of the top and bottom flanges of the test beams, referred to in $\$ \S 22,42$ and 44 gave results reminiscent of those obtained in tests on mild steel I-beams about 40 years ago at Battersea Polytechnic. ${ }^{43}$ On that occasion it was considered that the inconsistencies in the lateral deflexions were brought about mainly by variations in the cross sections of the I-beams.

71. Small variations occur in the cross sections of many commercial hot-rolled I-section bars, due to a number of causes during rolling. It is noted in $\$ 24$ that measurements of the test beam cross sections were made at a number of points along the length. It would be of interest to know, in view of the variations noted in the section moduli, what kind of differences were found in the sections of the test beams. For example, it is often found that the webs of beam sections are slightly eccentric with relation to the centre lines of the flanges. Also the outstanding legs of beam flanges may be of unequal mean thickness at a given cross section. Differences such as these would inhibit initial lateral movements and torsional displacements in a laterally unrestrained beam, as the loading increases or decreases.

72. Future proposals in $\$ \S 57-59$ for research are a modest appraisal of information still required by steelwork designers for a proper understanding of the behaviour of laterally unsupported I-beams. Up to the present, tests have been carried out only on concentrically loaded I-beams. But, as in the case of columns, loads are sometimes applied eccentrically to laterally unsupported beams, either intentionally or perhaps unintentionally, thus inhibiting additional torques into the loading systems. While some work on the theoretical effects of torsion has been initiated, ${ }^{44}$ no experimental investigations appear to have been carried out, so designers are often at a loss to know how to provide for such conditions. Perhaps problems of this kind might be investigated in some future researches on the subject. It is also suggested that the new steel section books should include the metric equivalents of the St Venant torsion constants of I-beam and column sections that would be useful for a number of purposes, instead of the $D / T$ ratios which are not difficult to calculate.

Professor Chin Fung Kee, Department of Engineering, University of Malaya, Malaysia

A very useful method for determining the elastic buckling load by analysing experimental data was produced by Southwell. ${ }^{45}$ It consists in measuring the deflexion $Z$ at various stages of the loading $H$; if $Z / H$ be plotted against $Z$ as the abscissa, the resulting relationship is linear and the inverse slope of this line gives the value of the buckling load. Although Southwell postulated this method for the case of the pinended strut, it was found to be valid for predicting the elastic buckling load of struts with other end conditions and of the tied arch. 46,47

74. I have plotted in Fig. 22 the results of the Author's tests 3, 9 and 28 . It will be seen from Fig. 22 that the relationships between $V$, the mean lateral deflexion of the cross section at midspan, and $V / P$ for the three tests are reasonably linear; $P$ being the applied load per jack. The inverse slopes of the lines give the ideal critical value of $P$ for the beams concerned. These values are $8 \cdot 12,7.61$ and $15.10 \mathrm{t}$ for tests 3,9 and 28 respectively. Because of imperfections, the ideal critical value of $P$ is not reached.

75. The maximum bending moment $M_{\mathrm{f}}$ that the beam will sustain will therefore be less than the ideal critical bending moment $M$.

76. The intercept which the Southwell plot makes with the abscissa is a measure of the imperfection. Of the three tests shown in Fig. 22, the intercept for test 9 is the smallest. 


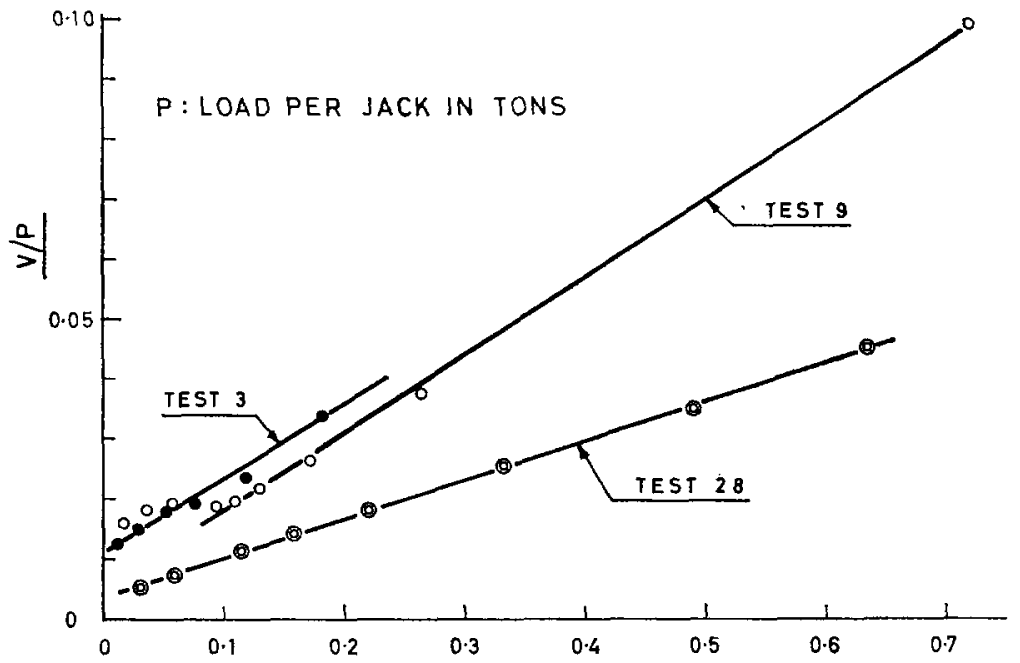

Fig. 22. Lateral deflexion

\section{Mr J. E. Dibley}

I am indebted to Dr Trahair for his elucidation of the effective length calculations for restrained beams based on his published work. I agree that equation (8) relates to the loading condition in which all spans are under a uniform bending moment, and that this leads to some conservatism in the estimation of values of $k_{\mathrm{L}}$. It should be pointed out that the effects of warping restraint are also not taken into account in this equation. These two factors have the greatest effect at large values of $a / L$. However, from Fig. 20 it can be seen that in the case of the test beams, where $a / L$ was in the range $0 \cdot 2-0 \cdot 5$, the resulting conservatism in the estimation of $k_{\mathrm{L}}$ was very small. An even smaller degree of conservatism results in the values of permissible stress that are subsequently obtained from the design curves; this would appear to be generally of the order $3-4 \%$.

78. With regard to the values of effective length factors obtained from ref. 24 , I had assumed the relation $M=\pi \sqrt{E I_{\mathrm{y}} G K / k_{\mathrm{L}}}$ in relating $\gamma_{1}$ to $k_{\mathrm{L}}$, i.e. $k_{\mathrm{L}}=\pi / \gamma_{1}$, in the absence of the definition of equation (9) which leads to a quartic expression in $k_{\mathrm{L}}$. If the factors quoted are divided into $\pi$ the result refers to the $\gamma_{1}$ values referred to in the reference. Effective length factors obtained from the quartic solution do give good agreement with other results, and I would therefore like to apologize for my previous misleading remarks.

79. It is interesting that the new Australian Code recommends an empirical curve (Fig. 21) which lies approximately midway between the curves of permissible stress obtained from the BS 449 (1959) Tables 3 and 4 . Good agreement with the empirical rule in my Paper is also obtained for $F=1.8$ and a maximum cutoff level of $P_{\mathrm{bo}} / Y_{\mathrm{s}}=0.66$.

80. I am not surprised that Mr Procter finds a similarity between equation (2) and the one he quotes since these are merely variations of the classical elastic critical stress equation. The essential differences are in the derivation of the permissible stress from the calculated critical stress. The aim of the work was to extend the range of permissible stresses given in the British Standards ${ }^{5.6}$ to include Grade 55 steel. 
For this reason the original equations ${ }^{4}$ were recalculated for the new steel and experiments carried out for verification.

81. Regarding Mr Procter's statement that the equation for critical stress does not apply to column sections with any degree of accuracy, I must refer him to ref. 4 in which calculations of the critical stress by the approximate and exact formulae were compared for a wide range of section shapes including those having $D / T^{\prime} \mathrm{s}$ in the column section range. It was concluded there that the approximate formula was perfectly satisfactory.

82. The tolerances on the variations of hot rolled I-sections are of course specified in BS 4 . The test beams were produced by a special rolling of the high yield strength steel and since this had to be fitted into the works rolling schedule at the end of the production run, eccentricities slightly greater than normal occurred. However, very little variation in shape and thickness occurred along the length of the beams, which is what one would expect. I do not agree that eccentricities inhibit the initial lateral and torsional movements of the beam; they merely change the section properties.

83. I agree that there are still many problems to be solved with regard to beam sections, including the effects of torsion on stability, and also bi-axial applied moments with or without end load. The proposals I made were specifically limited to beams loaded about the major axis only, and the steps which might be taken to achieve greater design stresses.

84. Professor Chin Fung Kee's observations on the lateral and torsional deflexions are of interest since this method can be used to determine the critical load of a member in a practical structure. Similar plots have been used for this purpose by Lazard ${ }^{48}$ in determining the collapse load of a strut member in a frame. However, since the theory postulates elastic behaviour the critical stress in a short member tends to be overestimated. The onset of plasticity will bring about an earlier failure than predicted.

\section{References}

30. Trahair N. S. The bending stress rules of the draft AS CA1. J. Instn Engrs Aust., 38, 6, 1966 (June) 131.

31. Tramair N. S. Elastic stability of I-beam elements in rigid-jointed structures. J. Instn Engrs Aust., 38, 7-8, 1966 (July-Aug.) 171.

32. Trahair N. S. Elastic stability of propped cantilevers. Civ. Engng Trans. J. Instn Engrs Aust., CE10, 1, 1968 (April) 94.

33. Trahair N. S. Elastic stability of continuous beams. Proc. Am. Soc. civ. Engrs, 1969, 95 (ST6), (June) 1295.

34. Trahair N. S. Interaction buckling of plane frames. Steel Construction, 1969,3 (1) 2.

35. TrahaIR N. S. Interaction buckling of narrow rectangular continuous beams. Civ. Engng Trans J. Instn Engrs Aust., 1968, CE10, 2 (Oct.) 167.

36. Brown P. T. and Trahair N. S. Finite integral solutions of differential equations. Civ. Engng Trans. J. Instn Engrs Aust., 1968, CE10, 2 (Oct.) 193.

37. LAY M. G. Flange local buckling in wide-flange shapes. Proc. Am. Soc. civ. Engrs, 1965, 91 (ST6) (Dec.) 95.

38. Terrington J. S. Combined bending and torsion of beams and girders. 31 (First Part), British Const. Steelwork Assoc., London, 1968.

39. Standards Association of Australia. Use of steel in structures. AS CA1: 1968.

40. Procter A. N. The solution of buckling problems by an approximate method. Engineering, London, 1937, 144 (Aug.) 144, 185. See also Appendix of ref. 43 below, 365-367.

41. Fisher CASsie W. and Dobie W. H. Torsional stiffness of structural sections. Struct. Engr, 1948, 26 (March) 182; also Civ. Engr, 1962, 16 (June) 297. 
42. Bethlehem Steel Company. Torsional stresses in structural beams. Bookiet 1803 (undated), also Civ. Engr, 1962, 16 (June) 298.

43. Procter A. N. Notes on the stability of columns and beams. Struct. Engr, 15, 1937 (Sept.) 357-361; see also MSc(Eng) thesis, London University, The stresses in and the stability of the flanges of rolled steel I-beams under various conditions of loading. Feb., 1931.

44. Procter A. N. Buckling under complex loading. Engineer, 1956, 201 (June) 629-630; also Engineer, 1960, 209 (April) 677.

45. Southwell R. V. Theory of elasticity. London, Oxford University Press, 1941.

46. Godden W. G. The lateral buckling of tied arches. Proc. Instn civ. Engrs, 1954, 3 (Pt III) (Aug.) 496-514.

47. Chin Fung Kee. The design of the unbraced Stabbogen arch. Struct. Engr, 1959 (Sept.) 265-270.

48. LAZARD A. Practical determination of the buckling load of a prismatic element. 106th Annual General Meeting of the Société des Ingénieurs Civils de France. 1965 (May). 